\title{
Differences in Learning Effects among Teachers Who Participate in Individual and in Groups in a MOOC
}

\author{
Shuang Li, Zhong Sun, and Liming Luo
}

\begin{abstract}
With the development of teacher education MOOCs, more and more schools encourage teachers to participate in MOOC. How to improve the learning effect of teachers has practical significance. Previous researches have mainly focused on the individual teachers who participate in the study alone. Little research has been done on the learning effects of the teacher groups. In this study, we adopt ANOVA and social network to analyze the differences in learning effects between teachers who participate in learning alone and teacher groups in a teacher education MOOC, and used interview to explore the causes of the differences. Results indicated: 1) the completion rate and excellence rate of group teachers are higher than individual teachers. Among them, the leader-guided teachers have higher academic performance. 2) in the forum, group teachers are more active. Effective strategies for teachers learning include three aspects: playing the exemplary role of model teachers, teachers establish a learning community, and the school establishes a learning support mechanism.
\end{abstract}

Index Terms-Teacher education MOOCs, group learning, teacher professional development, leadership.

\section{INTRODUCTION}

Ever since the advent of widespread MOOCs (Massive Open Online Courses), it has gradually become a main way for online teachers professional development [1]. However, the rapid development of MOOC cannot guarantee the quality of the courses, which leads to a reduction in the number of high-quality courses [2], and the practicality and pertinence of the curriculum resources are relatively scarce, unable to meet the actual needs of teachers and schools [3]. In this context, teacher Education MOOCs emerged. According to the actual needs of teachers, the curriculum team designs the systematic curriculum content, which provides an effective platform for teachers sustainable development in the digital era [4].

Previous teacher training focused more on improving individual knowledge and skills. The knowledge taught was not relate to the actual teaching environment in which teachers are located, so that many teachers with excellent performance could not really affect teaching and change performance after training. Nowadays, teachers training should be based on schools. The schools set the goals that teachers need to achieve, and organize teachers to participate

Manuscript received April 19, 2020; revised December 25, 2020. This research was partially funded by the National Science Foundation of China (Research on key technology of classroom teaching interactive analysis based on artificial intelligence, Grant Number: NSFC61977048).

The authors are with Capital Normal University, Beijing, China (corresponding author: Zhong Sun; e-mail: 18245882427@163.com, sunzhong@cnu.edu.cn, luolm@cnu.edu.cn). in learning collectively [5]. It has become a trend for teachers to participate in learning in groups. With the emergence of teacher education MOOCs, there are two forms of teacher participation in training, one form is in individual, and the other is in groups. Motivated by this fact, this study focus on the difference in the effect between teachers who participate in individual and in groups, and explores the reasons for the differences, provide suggestions for improving the effectiveness of online training for teachers.

\section{LITERATURE REVIEW}

\section{A. Group Learning}

The concept of group learning was originally proposed by the scholar Peter Senge. Group learning is a process, in which all members set the same goal, they learn together and play their own abilities, and finally achieve the goal [6]. Senge pointed that group learning is very important, because the basic learning units are groups rather than individuals. Chinese scholar Sang also believes that, humans should promote group learning in this society [7]. Group learning is not a simple combination of individual learners, but the cohesion among learners due to common goals. The learners form an indivisible learning community. In this community, there is a clear division of labor among learners. They share learning resources and solve problems together. Researchers generally agree with that group learn offers several benefits [8]. For example, when the group is in a learning atmosphere, the individual's growth rate is far faster than other forms of learning [9]. Besides learners have the opportunity to discuss learning content and share learning resources with others, which can use time efficiently and improve learning effectiveness [10]. And, when teachers study together, most teacher can share learning resources and exchange teaching experience. Despite these literature had given evidence for the strength of group learn for teacher growth, there is a limited amount of literature that focuses on group learn in the MOOC context.

\section{B. Influencing Factors of Group Learning Effect}

Psychologist Kurt Lewin pointed out in group dynamics, "Leaders are the core of the group and can affect the effectiveness of the group. Leaders with high ability can help maintain the relations of the group and promote the interaction of members to achieve the group goals [11]." Research focusing on leadership suggests that leaders often encourage group members, which can enhance their confidence and stimulate their learning motivation [12]. In the field of teaching, the principal is the highest person in charge of the school, principal leadership is reflected in many 
aspects. For example, the principal can influence the teaching work of the school, and can also formulate school-related policies and ensure the implementation of the policies. British scholar found that the process in which the principal exerts influence on teachers and students, it is the process teachers and students to achieve the expected goal [13]. D. Randy Garrison showed that the principal is the main factor to improve the professional qualities and change the way of learning of students and teachers [14].

In this context, this study aimed to explore the difference in learning effect between teachers who participate in learning alone and in groups in a teacher education MOOC, and whether leaders participation affects the effects of teachers in group learning was also studied. Therefore, we divided teachers into three types: 1) Individual participation is that the number of teacher in each school is less than or equal to 2.2) Group participation is that number of teacher in each school is more than 2, but without leader. 3) Leader-guided group participation is that the number of teacher in each school more than 2 and include the principal.

In summary, this study aimed to answer the following research questions:

1) Are there any differences in the grade of the three types teachers in online learning?

2) Are there any differences in online interactions of the three types teachers in forum?

\section{METHOD}

\section{A. Participants}

292 elementary teachers from seventeen respective provinces of China volunteered to engaged in this study. All of them took a seven week long professional development MOOC[URL]. Before the start of the class, we send pre-test questionnaires to investigate the basic information of teachers. According to statistics, individual participation is 46 teacher, group participation is 112 teachers, leader-guided group participation is 134 teachers, and in the type of leader-guided group participation 12 are principals.

\section{B. Data Source}

The first part of the data is the score, which is used to explore the differences between the online learning achievements of the three types of teachers. The total score is 100 , the passing score is greater than or equal to 60 points, and the excellent score is greater than or equal to 80 points.

The second part of the data is the messages in the forum post, which are used to study the differences of teachers online interaction. Deleted all expressions, symbols, pictures, daily communication messages and other messages that not related to learning, and finally collect 3453 pieces of valid messages as the research data. According to statistics, a total of 99 people participated in the discussion, 1 teaching assistant who posted the discussion topic, 1 lecturer, 8 teaching assistants, and 89 teachers. Among teachers, 27 is individual participation, 23 is group participation, and 39 is leader-guided participation.

The third part of the data is the interview, we interviewed 10 teachers randomly, each teacher's interview time was about 30 minutes. The topics of the interview: 1) The reasons for participating in online learning. 2) Whether colleagues or school leaders are helpful in the learning process. 3) What are the reasons for insisting on completing the learning. 4) Whether online interaction is helpful. In addition, 4 principals were interviewed to understand whether the school has established a certain mechanism or policy.

\section{Data Analysis}

Social network is the main research method for analyzing the relationships and characteristics of members [15]. This study used social networks to analyze the differences in online interactions among the three types of teacher. Researchers encoded the instructor, teaching assistants and teachers participating in the discussion. The teaching assistant who posts topics node was marked 1, the instructor's nodes was marked 2, the teaching assistants who solve problems were marked 3-10, each of the 89 teachers corresponds to a node named 11-99.

\section{RESUlts}

\section{A. Differences in Score among the Three Types of Teachers}

We compared the differences in completion rate, excellent rate and average score of the three types of teachers. The results show that leader-guided group participation learn effect best, and this type of completion rate, excellent rate and average score are the highest $(84 \%, 78 \%, 79$ points), followed by the group participation $(61 \%, 48 \%$ and 63 points), individual participation in academic performance is the worst $(52 \%, 41 \%$ and 56 points).

We conducted One-Way ANOVA tests to compare whether there are significant differences in the score of the three types of teachers. The results show that there are significant differences between the score of the three types of teachers, and the differences between groups can be compared, $F(2,286)=14.671, P<0.05$.

Post Hoc analysis using Least Significant Difference (LSD), table I shows the main results of ANOVA analysis, there was a significant difference between leader-guided group participation and individual participation $(p=0.00$ $<0.05$ ), there was a significant difference between leader-guided group participation and group participation $(p=0.00<0.05)$, there was no significant difference between individual participation and group participation $(p=0.420>$ 0.05). This means that teachers who participate in with the leader have higher grades and the teacher 's learning effect is better.

\section{B. Differences in Online Interactions among the Three Types of Teachers}

1) Social network diagram. As mentioned in the data collection section, a social network analysis was performed and a network diagram was produced. In the Fig. 1, the nodes shape of teaching assistants and instructor were marked diamond, individual participation were square, group participation were triangle, leader-guided group participation were circle. The position of the node and the number of arrows the node 
has is proportional to their contribution to the communication. As shown in the Figure 1, there are differences in the positions of the three shape nodes and the number of arrows in the three shapes. Most of the circle nodes were located in the middle of the community map, and the number of arrows is also the largest. The square and circle nodes were located at the edge of the community map, and the number of arrows were relatively small. The figure suggests teachers who participate in learning with leaders are more active online, they are willing to communicate with their peers and express their views.

TABLE I: ONE-WAY ANOVA OF THREE TYPES OF TEACHERS

\begin{tabular}{|c|c|c|c|c|c|c|}
\hline \multirow[b]{2}{*}{ (i) Type } & \multirow[b]{2}{*}{ (j) Type } & \multirow[b]{2}{*}{ Mean difference (i-j) } & \multirow[b]{2}{*}{ Std.error } & \multirow[b]{2}{*}{ Sig. } & \multicolumn{2}{|c|}{$95 \%$ Confidence interval } \\
\hline & & & & & Lower Bound & Upper Bound \\
\hline Individual & Group & -7.90118 & 5.61281 & .160 & -18.9488 & 3.1465 \\
\hline \multirow{3}{*}{ Group } & Leader-guided & $-25.14753 *$ & 5.48640 & .000 & -35.9464 & -14.3487 \\
\hline & Individual & 7.90118 & 5.61281 & .160 & -3.1465 & 18.9488 \\
\hline & Leader-guided & $-17.24635^{*}$ & 4.04577 & .000 & -25.2096 & -9.2831 \\
\hline \multirow[t]{2}{*}{ Leader-guided } & Individual & $25.14753 *$ & 5.48640 & .000 & 14.3487 & 35.9464 \\
\hline & Group & $17.24635^{*}$ & 4.04577 & .000 & 9.2831 & 25.2096 \\
\hline
\end{tabular}

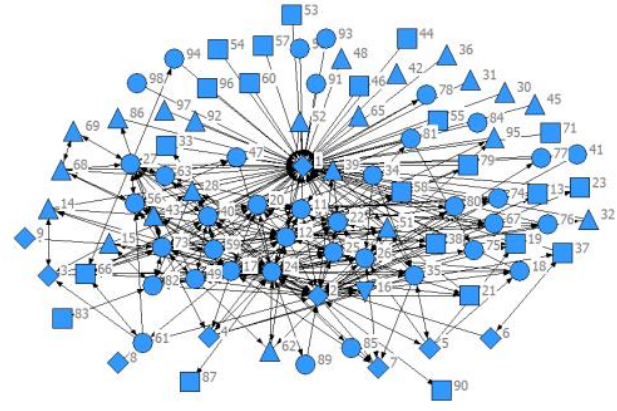

Fig. 1. Social network diagram.

2) Network Centrality. The concept of centrality is essential to evaluate the social status and influence of individuals in the network [16]. This study deleted the data of teaching assistants and instructor, and only analyzed the centrality of 89 participating teachers, which is prevent the numerical values of lecturers and teaching assistants from being too high and affecting the data results.

Degree centrality. Degree centrality can measure the enthusiasm of members to communicate. It was later found that the average value of the centrality is 5.34, of which the average degree of leader-guided group participation is 8.45 , group participation is 3.15 , and individual participation is 2.67. Figure 2 shows the degree centrality of the top 25 teachers, of which there are 18 people in leader-guided group participation, 6 people in group participation, and 1 individual participation. The figure suggests that the number of leader-guided group participation is the largest, with the highest average, followed by group participation, and individual participation are the worst.

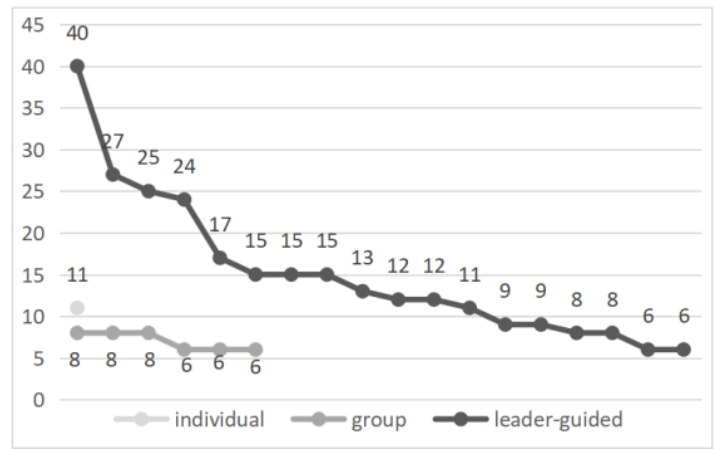

Fig. 2. The degree centrality of the top 25 teachers.

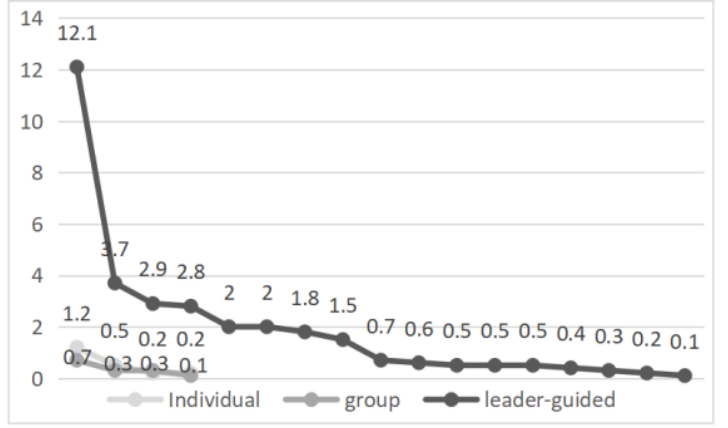

Fig. 3. The Betweenness Centrality of the top 25 teachers.

Betweenness Centrality. The Betweenness Centrality refers to the ability to connect members, it indicates the member's ability to deliver information and control resources in the network. We found that the average value of the centrality is 0.41 , of which the average degree of leader-guided group participation is 0.71, group participation is 0.17 , and the individual participation is 0.19 . Figure 3 shows the Betweenness centrality of the top 25 teachers, of which there are 17 people are leader-guided group participation, 4 people are group participation, and 4 are individual participation. It can be seen that leader-guided group participation has the largest number of people and the highest value, while the other two types have little difference.

\section{Analysis of Interview Results}

1) Leaders supervision and role model demonstration are teachers learning motivation. The results of the interview indicate that the leader's learning attitude will affect the teacher's learning attitude. The more the school leaders attach importance, the more serious the teachers will learn. As one teacher mentioned: "When you see the principal is busy every day, you will spend time studying hard and working hard." Another teacher mentioned: "I see older teachers can be serious I will feel ashamed when I am lazy to complete all the learning tasks."

2) Learning community is a necessary support for teachers to learn. According to interviews, it was found that teachers who participated in learning in groups can play a role of motivation and supervision. 7 teachers mentioned that colleagues play a supervisory role in reminding the course content and tasks and helping them to complete 
their homework on time, 4 teachers mentioned that they also provided guidance and help when they encountered difficulties in their studies. For example, a teacher mentioned that "When we encounter problems, we can discuss and solve the problems together."

3) External support is an important driving force for teachers to complete their studies. We found the principal setted up different forms of reward systems to support teachers to better complete the online courses during the learning process. A principal mentioned setting performance rewards for teachers who perform actively in discussions. One principal mentioned that the time of the online course is related to the evaluation of teachers, in order to motivate teachers to complete their studies. A principal said" our school arranges a teacher in charge to be responsible for online learning, and conducted a learning summary meeting to summarize teachers' learning this week and rewarded teachers with good learning performance once a week."

\section{DISCUSSION}

\section{A. Differences in Score among the Three Types of Teachers}

The results of the study found that the average score, completion rate, and excellent rate of the three types of teachers are different. Leader-guided group participation higher than group participation, and the individual participation is the worst. This implied that teacher groups participates in learning, they are more likely to complete the learning, with higher academic performance. Teacher interviews also show that during the learning process, teachers spontaneously formed a small learning community. In this community, teachers can discuss the course content, share learning resources, and remind each other of progress. Previous research shows that establishing a learning community is an effective way of learning [17].

Another finding is that the performance of leader-guided group participation is significantly different from the other two types. The interview data showed that some school established a support mechanism, such as promoting the learning progress and formulating a reward system, which can mobilize the enthusiasm of the teacher's learning. Previous studies have also shown that for teachers who lack internal motivation, external conditions support will become an important motivation for learning.

\section{B. Differences in Online Interaction among the Three Types of Teacher Groups}

By analyzing the social network above, this study found that teachers who participate in learning with colleagues are mostly distributed in the middle of the community map, while teachers who participate in learning alone are mostly distributed on the edge of the community map. It explains that teachers who participate in groups are more engaged in online interaction, and they are more willing to communicate with others, share their views [18].

Further research on centrality of the network, among the top 25 teachers in the central ranking, leader-guided group participation accounted for the largest proportion and the largest value. The interview data indicated that some leaders gave different forms of rewards to teachers who spoke positively. This finding is congruent to Hasu M's research, leaders encouragement and management can effectively stimulate teachers learning behaviors, which is beneficial to the learner's learning experience [19].

\section{Suggestions for Teacher Online Training}

At the individual level, playing the exemplary role of model teachers. Social cognition theory pointed, human beings can learn social behaviors by observing the behaviors of important people in their lives, as is the learning of teachers [20]. Model teacher refers to actively complet various learning tasks, and provide support and assistance to other teachers. Therefore, playing the demonstration and encouragement of core teachers, especially senior and older core teachers, driving other teachers to learn.

At the teacher level, a learning community with a good atmosphere is organized to enhance enthusiasm for learning [21]. It can enhance the sense of belonging of teachers. When the sense of belonging is basically satisfied, a higher level of cognitive needs will be generated. on the other hand, it is convenient for teachers exchange learning resources, and solve problems in time.

At the school level, establishing a motivation mechanism to stimulate teachers learning motivation. The schools can formulate an reward system to mobilize teachers enthusiasm for online learning and promote teachers high-quality completion of learning [22]. For example, the school can reward teachers who have completed their studies and obtained outstanding certificates. The school can also regards academic performance as an aspect of teacher performance evaluation, so that the level of academic performance is directly related to the teacher's title evaluation.

\section{CONCLUSION}

This study took a teacher education MOOC , and analyzed the differences among teachers who participate in individual and in groups from the aspects of academic performance and online interaction, and also explored whether leadership is the reason that affects the learning effect of teacher groups.Three effective strategies of teachers training in MOOCs are summarized: 1) Playing the exemplary role of model teachers. 2) Establishing a teachers learning community. 3) The school establishes a learning support mechanism.

\section{CONFLICT OF INTEREST}

The authors declare no conflict of interest.

\section{AUTHOR CONTRIBUTIONS}

Zhong Sun conducted the research; Shuang Li analyzed the data; Shuang Li wrote the original draft; Zhong Sun and Liming Luo reviewed and edited the final paper; all authors had approved the final version. 


\section{REFERENCES}

[1] S. Chen, B. Mulgrew, and P. M. Grant, "A clustering technique for digital communications channel equalization using radial basis function networks," IEEE Trans. on Neural Networks, vol. 4, pp. 570-578, July 1993.

[2] Laurillard and Diana, "The educational problem that MOOCs could solve: professional development for teachers of disadvantaged students," Research in Learning Technology, vol. 4, 2016.

[3] A. Margaryan, M. Bianco, and A. Littlejohn, "Instructional quality of massive open online courses (moocs)," Computers \& Education, vol. 80, pp.77-83, 2015.

[4] H. Khalil and M. Ebner, "MOOCs completion rates and possible methods to improve retention - A literature review," World Conference on Educational Multimedia, 2014.

[5] C. O. Fyle, "cTeacher education MOOCs for developing world contexts: issues and design considerations," presented at Sixth International Conference of MIT's Learning International Networks Consortium (LINC), 2013.

[6] H. B. Yan et al., "The direction and path of teachers' information technology ability training in the "Internet +" era," Distance Education in China, vol. 528, pp. 5-12, 2019.

[7] P. M. Senge, "The fifth discipline: the art and practice of the learning organization," Performance Improvement, vol. 30, pp.37-37, 2010.

[8] X.-M. Sang, "From individual learning to team learning: A new trend in contemporary learning theories and practice," Fudan Education Forum, vol. 4, pp. 11-13, 2015.

[9] P. D. Hudes et al., "Team-based learning in a gross annatomy and embryology course," Clinical Anatomy, vol. 18, pp.56-63,2005

[10] Dunaway and A. George, "Developments: adaption of team learning to an introductory graduate pharmacology course," Teaching \& Learning in Medicine, vol. 17, pp. 56-62, 2005.

[11] Y. F. Yang, C. I. Lee, and C. K. Chang, "Learning motivation and retention effects of pair programming in data structures courses," Education for Information, vol. 32, pp. 249-267, 2016.

[12] R. M. Williams, "Resolving social conflicts: selected papers on group dynamics.by kurt lewin;the more perfect union: A program for the control of inter-group discrimination in the united states.by r. $\mathrm{m}$ maciver," American Sociological Review, vol. 13, pp.778-779, 1948.

[13] T. Pinar et al., "The relationships between leadership behaviors team learning and performance among the virtual teams," International Business Research, vol. 7c, 2014.

[14] B. Tony and G. Derek, "School leadership models: What do we know?" School Leadership \& Management, vol. 34, pp. 553-571, 2014.

[15] D. R. Garrison and N. D. Vaughan, "Institutional change and leadership associated with blended learning innovation: Two case studies," The Internet and Higher Education, vol. 18, pp. 24-28, 2013.

[16] M. Oliveira and J. Gama, "An overview of social network analysis," Wiley Interdisciplinary Reviews Data mining \& Knowledge Discovery, vol. 2, pp.99-115, 2016.

[17] T. Opsahl, F. Agneessens, and J. Skvoretz, "Node centrality in weighted networks: Generalizing degree and shortest paths," Social Networks, vol. 32, pp. 245-251, 2010.
[18] T. Eunice, Lam, and Cherlotte, "Building an effective online learning community (OLC) in blog-based teaching portfolios," The Internet and Higher Education, vol. 20, pp. 79-85, 2014.

[19] P. Vesa, Hasu, and Mervi,“ Moderating effects of transformational leadership between external team learning and research team performance outcomes," $R \& D$ Management, vol. 45, pp. 304-316, 2015.

[20] B. R. Yvonne, H. Adelina, Jablokow, and W. Kathryn, "Exploring the relevance of single-gender group formation: What we learn from a massive open online course (MOOC)," British Journal of Educational Technology, 2016.

[21] B.-C. Simon, A. M. Leslie, and U. Frith, "Does the autistic child have a "theory of mind"," Cognition, vol. 21, pp. 0-46, 1985

[22] A. B. Rensfeldt, T. Hillman, and N. Selwyn, "Teachers 'liking' their work? exploring the realities of teacher facebook groups," British Educational Research Journal, vol. 4, 2018.

Copyright (C) 2021 by the authors. This is an open access article distributed under the Creative Commons Attribution License which permits unrestricted use, distribution, and reproduction in any medium, provided the original work is properly cited (CC BY 4.0).

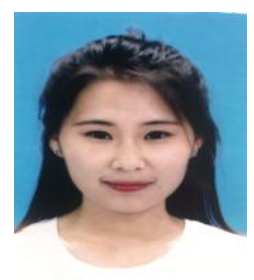

Shuang $\mathbf{L i}$ is a master student of Informational Engineering at Capital Normal University, Beijing, China. Her research interests include educational technology and learning analysis, and current research direction is mobile learning and technology enhanced teacher professional development.

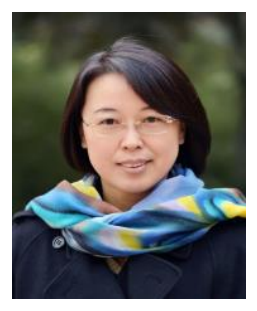

Zhong Sun is a professor in the College of Informational Engineering at Capital Normal University, Beijing, China. Her research interests include mobile learning and technology enhanced teacher professional development. Prof. Zhong Sun is the corresponding author of this paper.

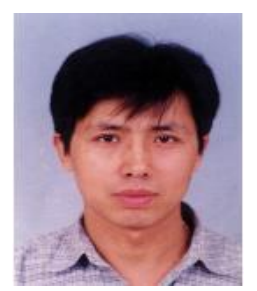

Liming Luo is a professor in the College of Informational Engineering at Capital Normal University, Beijing, China, and he is the head of the Computer Education Department. His research interests include software system construction and intelligent education. 